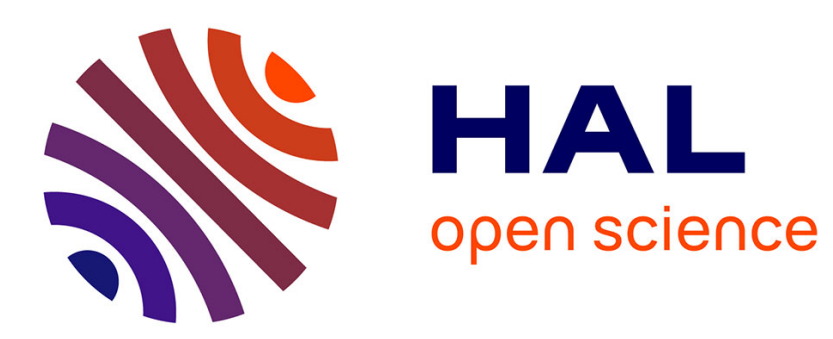

\title{
FIELD EVAPORATION OF IRON AND NIOBIUM IN NEON AND HYDROGEN
}

\author{
M. Wada, N. Akaiwa, S. Irumata, T. Mori
}

\section{To cite this version:}

M. Wada, N. Akaiwa, S. Irumata, T. Mori. FIELD EVAPORATION OF IRON AND NIOBIUM

IN NEON AND HYDROGEN. Journal de Physique Colloques, 1986, 47 (C7), pp.C7-21-C7-26. 10.1051/jphyscol:1986705 . jpa-00225894

\section{HAL Id: jpa-00225894 https://hal.science/jpa-00225894}

Submitted on 1 Jan 1986

HAL is a multi-disciplinary open access archive for the deposit and dissemination of scientific research documents, whether they are published or not. The documents may come from teaching and research institutions in France or abroad, or from public or private research centers.
L'archive ouverte pluridisciplinaire HAL, est destinée au dépôt et à la diffusion de documents scientifiques de niveau recherche, publiés ou non, émanant des établissements d'enseignement et de recherche français ou étrangers, des laboratoires publics ou privés. 


\title{
FIELD EVAPORATION OF IRON AND NIOBIUM IN NEON AND HYDROGEN
}

\author{
M. WADA, N. AKAIWA, S. IRUMATA and T. MORI \\ Department of Materials Science and Engineering, Tokyo \\ Institute of Technology, 4259 Nagatsuta, Midori-ku, \\ Yokohama 227, Japan
}

\begin{abstract}
Field evaporation of iron and niobium in neon and in hydrogen was examined between $20 \mathrm{~K}$ and $200 \mathrm{~K}$ with an FIM. From the temperature dependence of the evaporation field and the field dependence of the evaporation rate, the activation energy for the evaporation was estimated and the effect of hydrogen was discussed.
\end{abstract}

\section{I - INTRODUCTION}

Field evaporation is a removal of surface atoms by a high electric field $/ 1 /$ and is directly observed by a field ion microscope. It has been known that the presence of hydrogen on a metal surface promotes field evaporation $/ 2 /$ and reduces the applied field for a given evaporation rate, or the evaporation field $/ 3 /$. It has been shown that the evaporation field of iron in hydrogen atmosphere is considerably smaller than that in neon. This reduction of the evaporation field is probably related to the reduction of binding energy of surface atoms of iron by adsorbed hydrogen on iron surface. If the field evaporation both in neon and in hydrogen can be described by the charge-exchange model /4/, it is possible to determine the reduction of the binding energy of surface atoms from the measured reduction of the evaporation field. As it has been indicated, however, the temperature dependence of the evaporation field in neon below about $150 \mathrm{~K}$ is not consistent with the charge-exchange model and a different ratecontrolling process for the evaporation must be considered $/ 5 /$. In order to study the reduction of the evaporation field by hydrogen, it seems important, therefore, to examine closely the evaporation behavior in neon and hydrogen. In the present study, temperature dependence of the evaporation field and field dependence of the evaporation rate are measured in neon and hydrogen between $20 \mathrm{~K}$ and $200 \mathrm{~K}$; and activation energy for the evaporation was estimated.

The effect of hydrogen on the field evaporation of iron is likely to be due to the adsorbed hydrogen atoms on iron surface, since the solubility of hydrogen in iron at low temperatures is very small. Contrary to iron, niobium absorbs hydrogen and forms hydrides at low. temperatures. It has been shown that the dissolved hydrogen atoms in niobium affect the FIM image $/ 6 /$. It may be interesting, therefore, to study the field evaporation of niobium in a presence of hydrogen 
and to compare the results with those of iron.

\section{II - EXPERIMENTAL}

Iron (99.9\%) and niobium(99.9\%) wires, $0.2 \mathrm{~mm}$ thick, were used for specimens after electropolishing at one ends in solutions; $\mathrm{H}_{2} \mathrm{O}(2 \mathrm{pt}$.), $\mathrm{HCl}$ (lpt.) and $\mathrm{HNO}_{3}$ (lpt.) at $220^{\circ} \mathrm{C}$ and $\sim 4 \mathrm{~V}$ ac for iron, and $\mathrm{H}_{2} \mathrm{SO}_{4}(5 \mathrm{pt}$ ), $\mathrm{HNO}_{3}$ (2pt.) and $\mathrm{HF}(1 \mathrm{pt}$.$) at \sim-40^{\circ} \mathrm{C}$ and $\sim 10 \mathrm{~V}$ dc for niobium. The FIM used was equipped with a cryogenic refrigerator and temperature of a specimen could be continuously changed down to $20 \mathrm{~K}$. Two kinds of measurements were made. One was to determine the temperature dependence of an applied voltage at which the (011) planes on a nearly spherical surface of a specimen tip were removed at a rate of about 0.1 layers/s. This was done by directly observing the field evaporating atomic planes by the FIM with neon and/or hydrogen. The other was to measure the applied voltage dependence of the evaporation rate. This was done by analyzing the video-recorded FIM images, time and voltage during field evaporation. The measured evaporation rate centered at $10^{-1}$ layers/s and covered approximately two or three orders of magnitude. In both measurements, the voltage increase due to the increase of tip radius was corrected.

Hydrogen content in niobium specimen before field evaporation and the exposure to hydrogen atmosphere in the FIM chamber is not known. Attempts were made to reduce the initial hydrogen content by heating the niobium tip at $\sim 10^{-7} \mathrm{~Pa}$ after obtaining a clear FIM image in neon. Unfortunately, the heating sometimes deteriorated the quality of reon images and made the following measurements of the evaporation voltage and the evaporation rate difficult. Therefore non-heated specimens were used. The neon images of non-heated specimens, however, were very similar to that thoroughly outgassed specimen by Krautz et al./6/ and no dark regions due to dissolved hydrogen on the image was recognized. We consider, therefore, that the amount of hydrogen originally contained in the specimen which had been field-evaporated in neon and kept in the FIM chamber at a partial pressure of residual hydrogen gas of less than $10^{-8} \mathrm{~Pa}$ is sufficiently small and does not influence significantly the present results or at least the qualitative trend of the results.

\section{III - RESULTS AND DISCUSSION}

(a) Results for ixon

Figure I shows the temperature dependence of the applied field for the evaporation of (011) planes at $10^{-1}$ layers/s. The field $F$ which we call evaporation field here is assumed to be proportional to the applied voltage and is normalized by $F_{\circ}$, the extrapolated value of $F$ at $0 \mathrm{~K}$. The evaporation field in hydrogen is also normalized by the same $F_{0}$. Neon and hydrogen pressures are $7 \times 10^{-3} \mathrm{~Pa}$ and $6 \times 10^{-3} \mathrm{~Pa}$, respectively. A large temperature dependence of $F$ in neon and a large reduction of $\mathrm{F}$ by hydrogen is seen. Temperature dependence of $\mathrm{F}$ in hydrogen is quite smooth, contrary to the previously reported dependence in which a step-like change of $F$ at about $85 \mathrm{~K}$ has been observed $13 /$. The present study has found that the step was an artifact due to a small amount of $\mathrm{N}_{2}$ or $\mathrm{CO}$ contained in hydrogen whose partial pressure rapidly decreased at the tip temperature of $85 \mathrm{~K}$ as the temperature of the refrigerator surface was decreased. Figure 2 shows the field dependence of the evaporation rate. The data indicated by open symbols are those in neon and solid symbols in hydrogen.

(b) Results for niobium

Figure 3 shows the temperature dependence of the evaporation field. Figures $4(\mathrm{a}), 4(\mathrm{~b})$ and $4(\mathrm{c})$ are the field dependence of the evaporation rate. They are mesasured under three different conditions; (1) in pure neon gas at $3 \times 10^{-3} \mathrm{~Pa}$, (2) in a mixture of $3 \times 10^{-3} \mathrm{~Pa}$ of neon and $1.4 \times 10^{-3} \mathrm{~Pa}$ of hydrogen after field evaporation and exposure for 30 


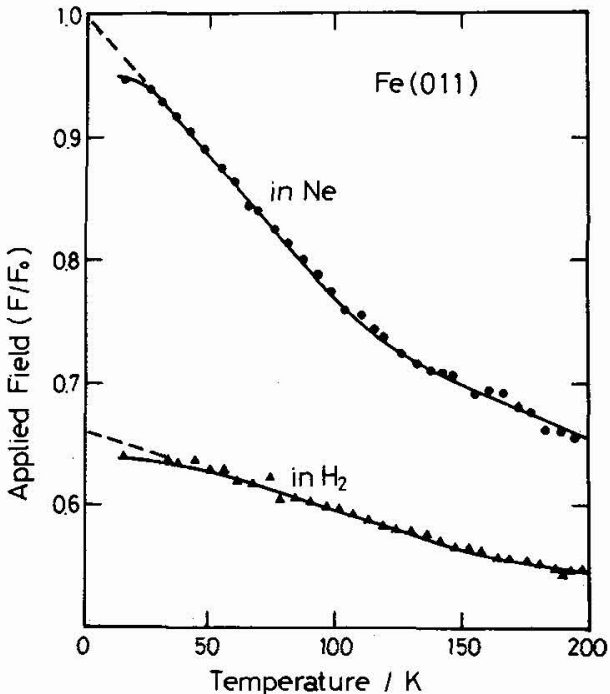

Fig. I Temperature dependence of evaporation field of $F e$ in neon $\left(7 \times 10^{-3} \mathrm{~Pa}\right)$ and in hydrogen $\left(6 \times 10^{-3 \mathrm{~Pa})}\right.$.

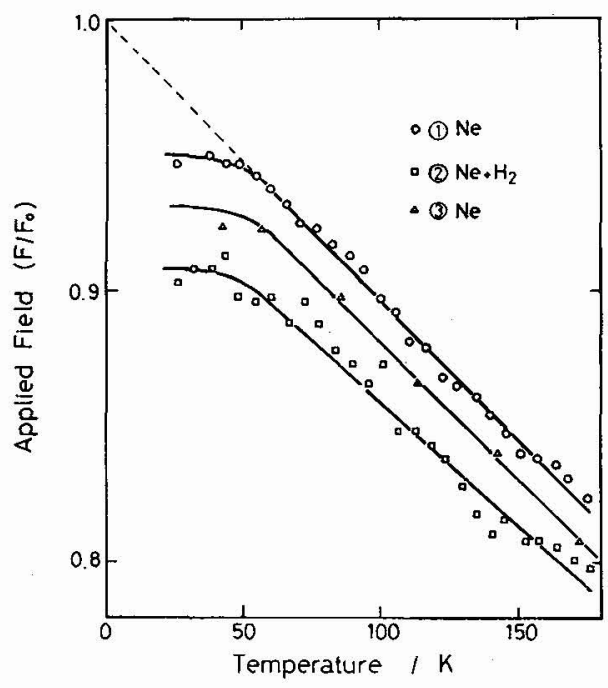

Fig. 2 Temperature dependence of evaporation field of $\mathrm{Nb}$ under three conditions (1), (2) and (3). see text for the conditions.

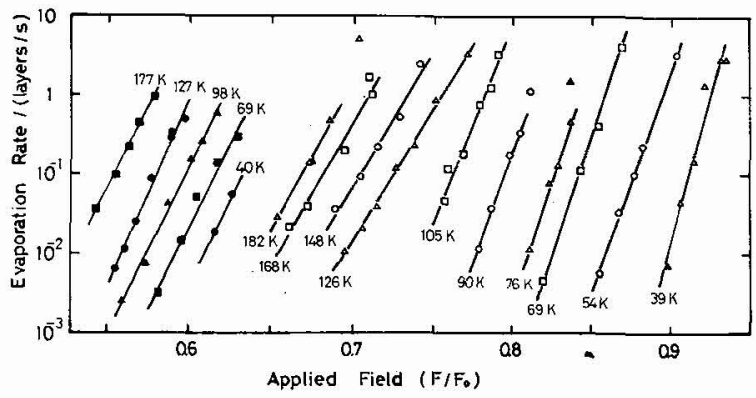

Fig. 3 Field dependence of evaporation rate of $\mathrm{Fe}$. open symbols are those in neon $\left(7 \times 10^{-3} \mathrm{~Pa}\right)$ and solid symbols in hydrogen $\left(6 \times 10^{-3} \mathrm{~Pa}\right)$.

min. in the same mixtured gas, and (3) again in $3 \times 10^{-3} \mathrm{~Pa}$ of neon after the mixtured gas containing hydrogen has been completely evacuated. The partial pressure of hydrogen in condition (3) is less than 10-7Pa. The results under condition (3) remained the same even after about 100 layers of (011) planes had been removed. Therefore, the reduced evaporation field in neon of specimens once exposed to hydrogen gas (condition (3)) compared to the field before the exposure (condition (1)), and also the different slopes between Figs. $4(a)$ and 4 (c) can be attributed to the effect of hydrogen dissolved in niobium. The larger reduction of the evaporation field in condition (2) and the smallest slopes in Fig. $4(\mathrm{~b})$ compared to those under condition (1) are due probably to the dissolved hydrogen as well as adsorbed hydrogen on the niobium tip surface. Results for iron under such a condition as (3), on the other hand, are the same as those before the hydrogen exposure, indicating that the effect of hydrogen is due only to adsorbed hydrogen atoms on iron surface. 

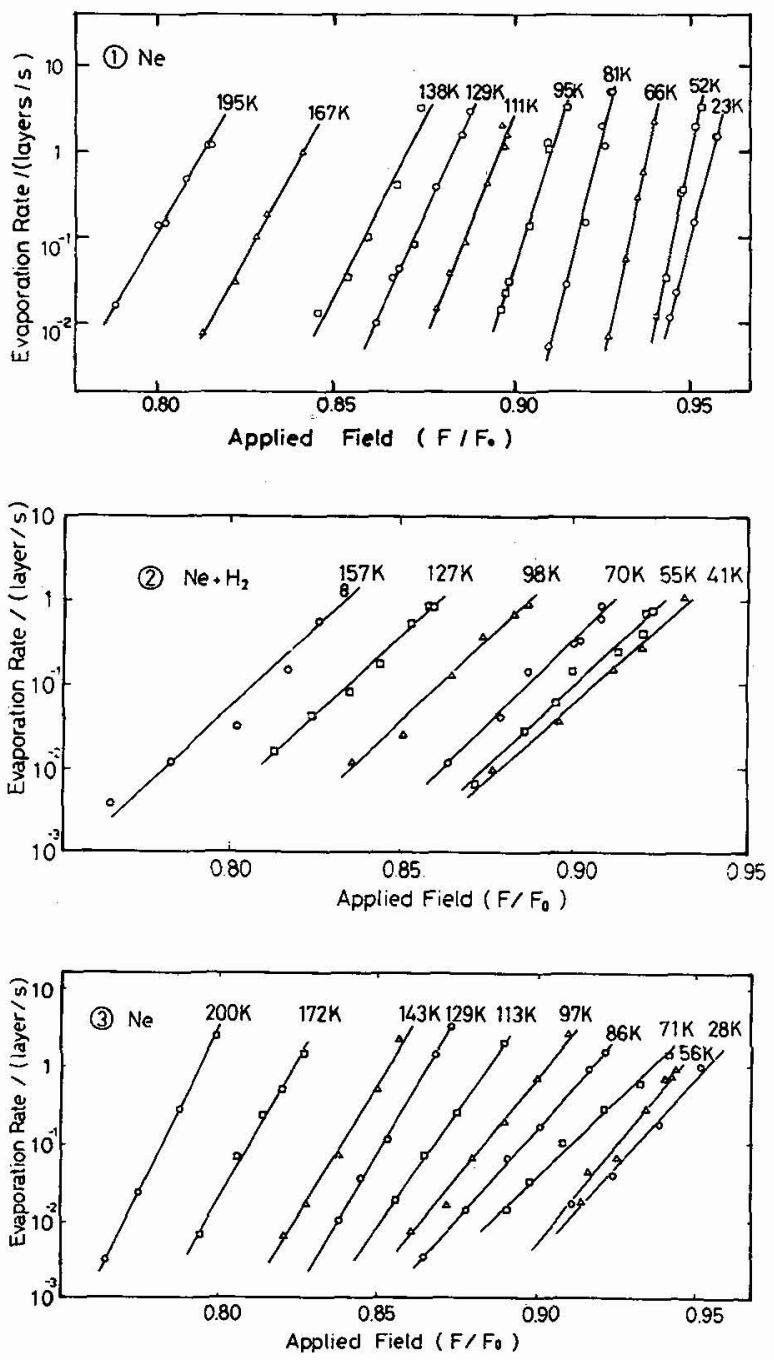

Fig. $4(\mathrm{a})$

Field dependence of evaporation rate of niobium in neon before exposure to hydrogen (condition (1)). $\mathrm{Ne}: 3 \times 10^{-3} \mathrm{~Pa}$
Fig. $4(b)$

Field dependence of evaporation rate of niobium in a mixture of neon and hydrogen (condition (2)) . Ne: $3 \times 10^{-3} \mathrm{~Pa}, \mathrm{H}_{2}: 1.4 \times 10^{-3} \mathrm{~Pa}$

Fig. $4(\mathrm{c})$

Field dependence of evaporation rate of niobium in neon after exposure to hydrogen (condition (3)). Ne: $3 \times 10^{-3} \mathrm{~Pa}$

(c) Thermal activation analysis

Above results are analyzed by assuming that the evaporation rate is described by the Arrhenius equation,

$\gamma=\gamma_{0} \exp (-Q / k T)$

where $\gamma$ is the rate constant, $\gamma_{0}$ the pre-exponential, $Q$ the activation energy, $\mathrm{k}$ the Boltzmann constant and $\mathrm{T}$ the temperature. The evaporation rate $\mathrm{J}$ in layers/s on the (011) plane is related to $\gamma$ by

$\mathrm{J}=\mathrm{n}_{\mathrm{hr}} \boldsymbol{\gamma}$,

where $\mathrm{n}_{\mathrm{hr}}$ is the amount of materials in layers at high risk of field evaporation $/ 7 /$ and is assumed constant. Assuming further that $Q$ is a function of only $F$ and $\gamma_{0}$ is independent of $T$, we obtain

$Q=-k T^{2}\left(\frac{\partial \operatorname{In} \gamma}{\partial F}\right)_{T}\left(\frac{\partial F}{\partial T}\right)_{\gamma}=-k T^{2}\left(\frac{\partial \ln J}{\partial\left(F / F_{0}\right)}\right)_{T}\left(\frac{\partial\left(F / F_{0}\right)}{\partial T}\right)_{J}$ 
for a constant $\mathrm{J}$ or $\gamma$. Values of $\left(\partial \ln \mathrm{J} / \partial\left(\mathrm{F} / \mathrm{F}_{0}\right)\right)_{\mathrm{T}}$ and $\left(\partial\left(F / \mathrm{F}_{0}\right) / \partial \mathrm{T}\right)_{\mathrm{J}}$ in eq. (3) can be obtained from the slope in Figs. 3 and 4 at $\mathrm{J}=0.1 \mathrm{~J}$ layers/s and from the slope in Figs. 1 and 2, respectively. Therefore, $Q$ can be determined and the results are plotted against temperature in Figs. 5 and 6 for iron and niobium, respectively. The variation of $Q$ with $T$ of both iron and niobium under the effect of hydrogen, squares in Fig. 5 and squares and triangles in Fig. 6, is quite smooth within the examined temperature range; $Q$ increases monotonically with $T$. In neon, Q - T curves for iron and niobium are not simple. Figure 5 clearly suggests that the rate-controlling process for the evaporation of iron can not be described by a single process and it appears that different processes should be considered below $0100 \mathrm{~K}$ and above $150 \mathrm{~K}$. The Q - T relation for niobium in neon is qualitatively similar to that of iron and it is also difficult to explain the relation by a single rate-controlling process. According to eq. (1), $Q$ should be proportional to $T$ for a constant $\gamma$. The deviation from the proportionality is then due to a variation of $\gamma_{0}$ with $F$. The smaller values of $Q$ under the effect of hydrogen compared to those in neon are due to smaller values of $\gamma_{0}$, since $\gamma$ is the same in all the cases.

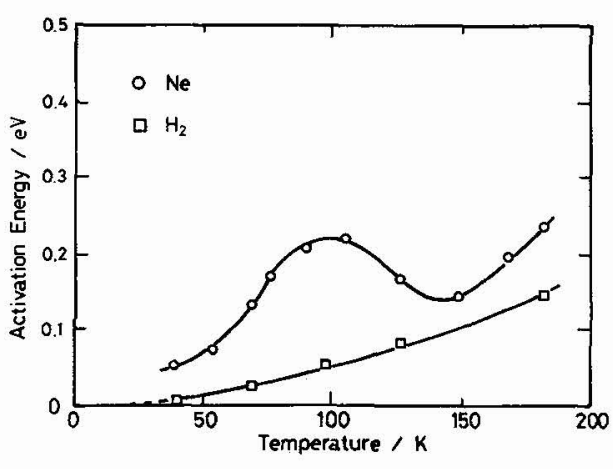

Fig. 5 Variation of activation energy for iron at a constant evaporation rate, $10^{-1}$ layers/s, with temperature.

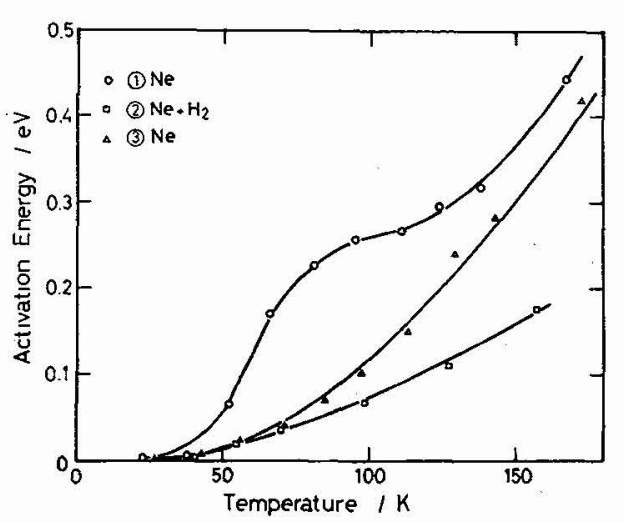

Fig. 6 Variation of activation energy for niobium at a constant evaporation rate, $10^{-1}$ layers/s, with temperature. Upper, middle and lower curves are under conditions (1), (3) and (2), respectively.

It is suggested that the rate-controlling process for the field evaporation of iron in neon below about $100 \mathrm{~K}$ is the short-range migration of evaporating atoms just before the evaporation and it is the field evaporation process itself described by the charge-exchange model above $150 \mathrm{~K} / 5,8 /$. A reasonably similar trend of $Q-T$ curve for niobium in neon, upper curve in Fig. 6, to that for iron in neon in Fig. 5 seems to indicate that a similar argument can also be made for the rate-controlling process of the field evaporation of niobium in neon.

The pre-exponential factor $\gamma_{0}$ can be obtained from eqs. (1) and (2) as, In $\gamma_{0}=\ln \mathrm{J}-\ln \left(\mathrm{n}_{\mathrm{hr}}\right)+\mathrm{Q} / \mathrm{kT}$.

The variation of $\gamma_{0}$ with $T$ is shown in Figs. 7 and 8 for iron and niobium, respectively, assuming $\mathrm{n}_{\mathrm{hr}}=0.1$ layers $/ 8 /$. 


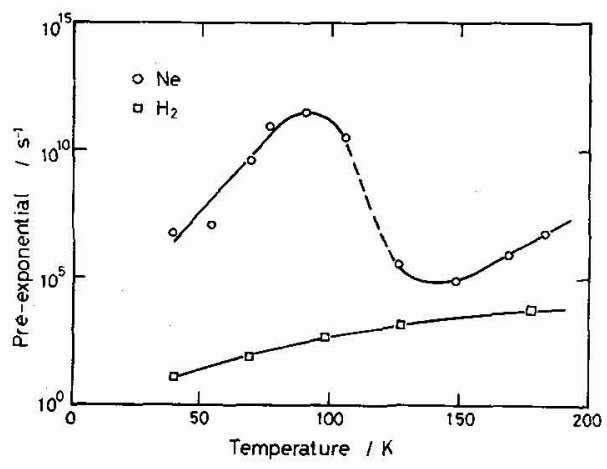

Fig. 7 Change of pre-exponential factor $\gamma_{0}$ of iron at a constant evaporation rate, $10^{-1}$ layers/s, with temperature.

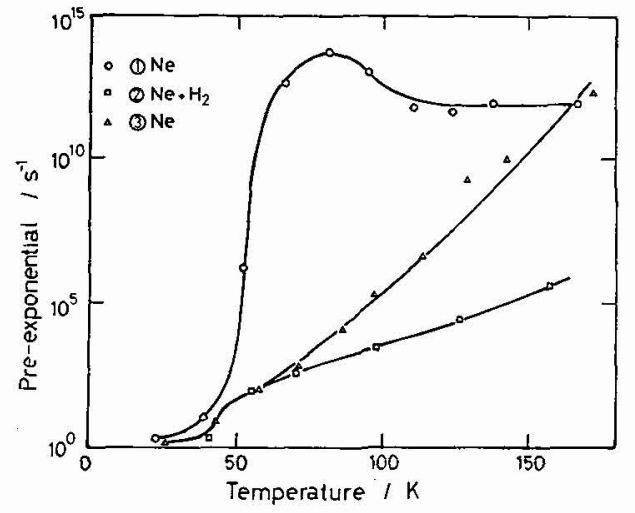

Fig. 8 Change of pre-exponential factor $\gamma_{0}$ of niobium at a constant evaporation rate, $10^{-1}$ layers/s, with temperature.

We have assumed that $\left(\partial \ln \gamma_{0} / \partial T\right)_{F}=0$. If this is justified, the obtained variation of $\gamma_{0}$ with $T$ is solely due to the change of $\gamma_{0}$ with $F$, since $F$ at a constant evaporation rate depends on $T$. It is seen that $\gamma_{0}$ under the influence of hydrogen is surprisingly smaller than the vibrational frequency of metal atoms which is of the order of 1012 /s. Explanations for $\gamma_{0}$ of less than $105 / \mathrm{s}$ for iron and niobium in hydrogen atmosphere are not available. It can be shown that the low values of $\gamma_{0}$ for iron in neon below $100 \mathrm{~K}$ are explained by a tunneling of evaporating atoms through the activation barrier for the short-range migration process. $\gamma_{0}$ for niobium in neon (condition (1)) above $\sim 70 \mathrm{~K}$ is close to the vibrational frequency. Quite low values of $\gamma_{0}$ at low temperatures is likely to be due to the tunneling effect as in the case of iron.

The present results can be summerized as follows. Evaporation field of niobium is reduced by both adsorbed hydrogen on the surface and dissolved hydrogen in niobium, while the reduction of the evaporation field of iron by hydrogen is due to the adsorbed hydrogen on iron surface. Presence of hydrogen reduces the activation energy for the field evaporation of iron and niobium. The pre-exponential factor under the influence of hydrogen is quite small compared to the vibrational frequency of atoms. Field evaporation of iron and niobium in neon cannot be described by a single rate-controlling process.

\section{REF ERENCES}

/1/ Müller, E.W. and Tsong, T.T., Field Ion Microscopy, Principles and Applications (Elsevier, Amsterdam, 1969)

/2/ Müller, E.W., Nakamura, S., Nishikawa, O. and Mclane, S.B., J. App1. Phys. 36 (1965) 2496.

/3/ Wada, M., Uemori, R. and Nishikawa, O., Surface Sci. 134(1983) 17.

/4/ Gomer, R. and Swanson, L.W., J. Chem. Phys. 38 (1963) $\overline{1613}$.

/5/ Wada, M., Surface Sci., 145(1984) 451 .

/6/ Krautz, E., Polanschütz, W. and Haimi, G., Proc. 29 th International

Field Emission Symposium (Almovist \& Wiksell. International, Stockholm

1982) p. 151 .

/7/ Forbes, R.G., Surface Science 46(1974) 577 .

18/ Wada, M., Akaiwa, N. and Mori, T., to be published in Phil. Mag. 